\title{
Development Processes of the Tropical Pacific Meridional Mode
}

\author{
Shu Wu ${ }^{1}$, Lixin Wu, Qinyu Liu \\ Physical Oceanography Laboratory, Ocean University of China, Qingdao, China
}

\section{Shang-Ping Xie}

International Pacific Research Center and Department of Meteorology, University of Hawaii, Honolulu, USA

\section{ADVANCES IN ATMOSPHERIC SCIENCES}

April 11, 2008, submitted

February 27, 2009, revised

${ }^{1}$ Corresponding author: Shu Wu, Physical Oceanography Lab., Ocean University of China, 238 Songling Road, Qingdao 266100, China.

Email: martialartws@hotmail.com 


\begin{abstract}
Mechanisms for the spatio-temporal development of the Tropical Pacific Meridional Mode (TPMM) are investigated using a coupled ocean-atmosphere model and observations. In both observation and the model, this meridional mode displays decadal variations and is most pronounced in spring and early summer. The model simulation suggests that once sea surface temperature (SST) anomalies in the subtropical northeastern Pacific are initiated, say by northeastly trade wind variability, they evolves into a merdional dipole in 2-3 months. The wind-evaporative-SST feedback causes a southwestward propagation of initial subtropical SST anomalies while anomalous equatorial upwelling helps form the southern lobe of the meridional dipole. The TPMM development is a fast process (a few months) and depends on the seasonal cycle.
\end{abstract}

Key words: Tropical Pacific Meridional Mode; wind-evaporative-SST feedback; oceanic upwelling; decadal variation; seasonal phase lock 


\section{Introduction}

El Niño-Southern Oscillation (ENSO) is the dominant mode of the tropical Pacific ocean-atmosphere system, exerting profound impacts on the global climate (Klein et al., 1999; Alexander et al., 2002). The dynamics and prediction of ENSO have been extensively studied over the recent decades (e.g., Wang and Picaut ,2004). Recent observational studies suggest that there is an additional mode in the eastern tropical Pacific, with a center of sea surface temperature (SST) anomalies north of the equator coupled with changes of the northeastly trade winds and shifts of the intertropical convergence zone (ITCZ; Fig. 1a). This mode is referred to as the Tropical Pacific Meridional Mode (TPMM), and analogous to the tropical Atlantic meridional mode (Chiang and Vimont, 2004; CV04 hereafter). As a trigger for the TPMM, extratropical atmospheric variability can cause SST anomalies in the subtropical northeastern Pacific by varying the northeastly trade winds and surface evaporation (Vimont et al., 2001, 2003; Wu et al., 2007; Chang et al., 2007). It is unclear, however, how these subtropical SST anomalies can develop into the TPMM, with substantial tropical SST anomalies including the cold lobe in the equatorial eastern Pacific (Fig. 1a).

The present study tests the hypothesis that atmospheric-forced SST anomalies in the subtropics can develop subsequently into a meridional dipole with cooling near the equator, using the initial-value problem approach with a coupled model that simulates major features of the observed merdional mode in the free run. We will investigate the mechanisms for the spatial-temporal development of the TPMM. Section 2 describes the observational data and the model used in this study. Section 3 
compares the TPMMs in the model simulation and observations. Section 4 presents the results from the initial value problem and studies ocean-atmosphere interaction in the formation of the meridional mode. Section 5 is a summary and further discussion.

\section{Observations and Model}

We use the HadISST dataset on a $1^{\circ}$ grid for SST and the NCEP reanalysis on a $2.5^{\circ}$ grid for $1000 \mathrm{hPa}$ wind velocity from January 1948 to December 2002. The Fast Ocean- Atmosphere Model (FOAM; Jacob, 1997; http://www-unix.mcs.anl.gov/foam/) is used, which has a tropical climatology typical of state-of- art climate models (Davey et al., 2002) and produces a reasonable ENSO (Liu et al., 2000). The atmospheric model has R15 resolution with 18 vertical levels, and the ocean model is solved on a $1.4^{\circ}$ latitude $\times 2.8^{\circ}$ longitude grid with 32 vertical levels.

The control run is integrated for 100 years. In analyzing observations and model simulations, we first calculate the monthly mean anomaly by removing the mean seasonal cycle, and then apply a 3-months running mean. We use the Maximum Covariance Analysis (MCA, also called singular value decomposition; Bretherton et al., 1992) to extract coupled modes of SST and wind variability.

\section{Observed and model-simulated TPMM}

In observations, the first MCA mode is ENSO, with SST anomalies centered on the equator and changes in the easterly trade winds in the eastern tropical Pacific (not shown). The second MCA mode (Fig.1a) is a meridional SST dipole, with a northeast-oriented lobe extending from the California coast to the central equatorial Pacific, and a lobe on and slightly south of the equator with the opposite polarity. This 
SST dipole with warm (cold) anomalies north (south) of the equator is associated with a reduction (enhancement) of the northeastly (southeastly) trade winds and anomalous southerly cross-equatorial winds, forming a C-shape pattern as observed in the tropical Atlantic. This meridional mode is detected as the second mode in an empirical orthogonal function (EOF) analysis for SST, accounting for 9\% of the total SST variance.

The TPMM exhibits temporal variations distinct from ENSO. In observations, the ratio of SST variance between decadal ( $>8$ years) and interannual (2-7 years) timescales is 0.4 for ENSO mode and 1.1 for the TPMM, respectively. Thus, the TPMM tends to be dominated by decadal and ENSO by interannual variability. Furthermore, the TPMM shows a seasonal phase lock different from ENSO, with strongest amplitudes in May-June (Fig.1c). SST variance peaks in early winter for the ENSO mode (not shown). The TPMM here is similar to that in CV04 but the southern lobe appears more robust in our analysis. This slight difference is perhaps due to the differences in observational data and statistical method to removing ENSO. CV04 removes ENSO by subtracting a linear least-square fit to a cold tongue index while we do so by MCA mode decomposition.

In the control simulation, the first and third MCA modes of SST and surface winds in the tropical Pacific are the ENSO (not shown) and the TPMM (Fig.1b), respectively. The simulated TPMM resembles observations, with a meridional SST dipole coupled with anomalous C-shape winds. Compared to observations, the southern lobe of the simulated TPMM is somewhat shifted to the west away from the coast while the 
northern lobe has weaker amplitudes in the central equatorial Pacific. In the model TPMM appears as the second EOF mode for SST and accounts for about $9 \%$ of the total variance, the same as in observations. The model TPMM displays substantial decadal variability (not shown) and a distinctive seasonal phase lock (Fig.1c). The model TPMM peaks in June-July, lagging the observations by one month. 

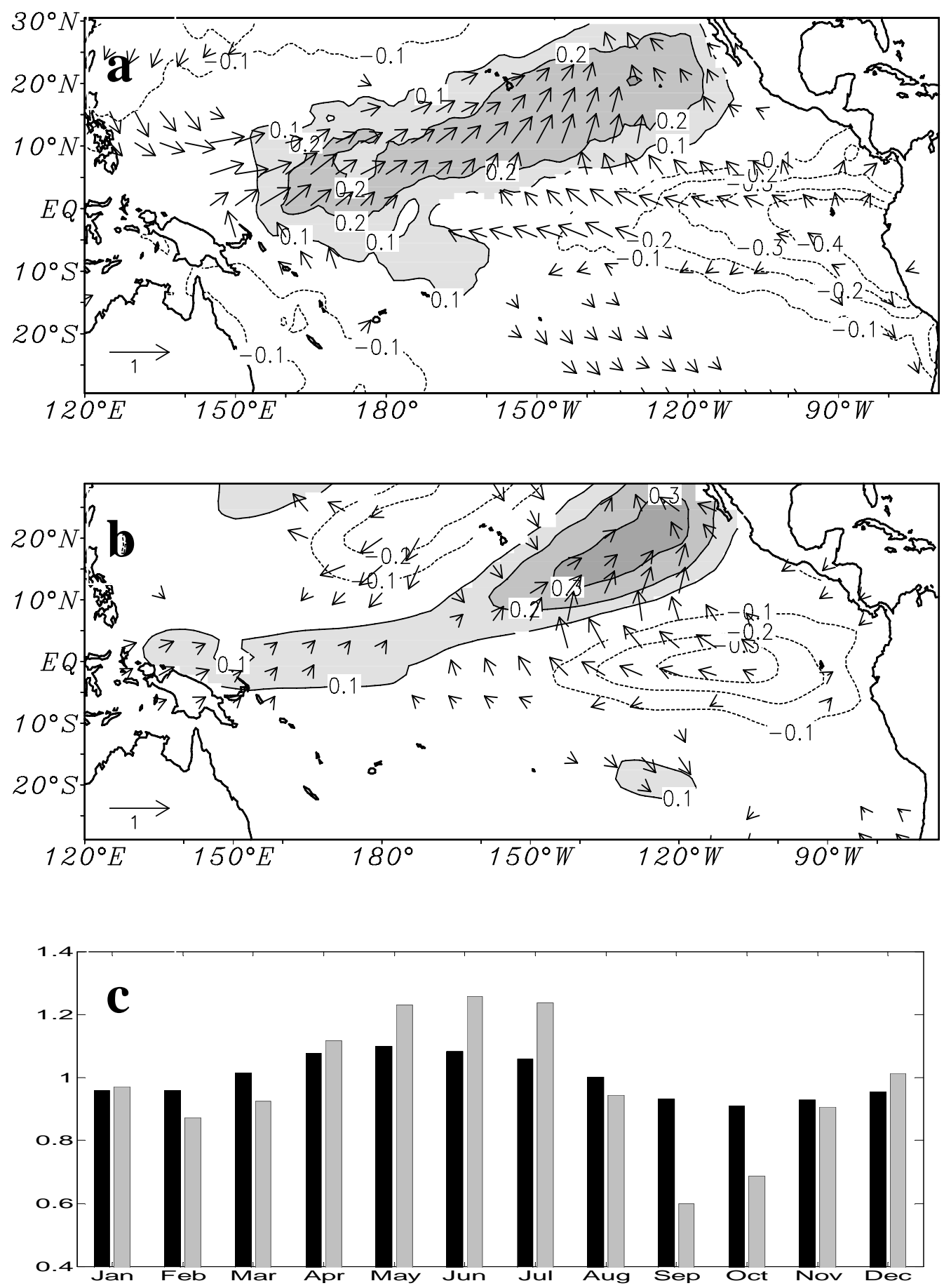

Months

Fig.1. Tropical Pacific meridional mode as represented by regression of SST (contours in ${ }^{\circ} \mathrm{C}$ ) and surface wind velocity (in $\mathrm{ms}^{-1}$ ) against the normalized expansion coefficient of the relevant MCA mode in (a) observations (b) the model simulation. Only values that exceed the $95 \%$ level of statistical significance are plotted. (c) 
Standard deviation of SST expansion coefficients in observations (black bars) and the model (grey).

\section{Sensitivity experiment}

The TPMM explains a small fraction of total SST variance in the tropical Pacific ( $~ 9 \%$ in both observations and the model). With a short observational record ( $<60$ years), it is difficult to establish conclusively that the TPMM is not an artifact of statistical analyses. Since the FOAM reproduces the statistical TPMM, we proceed to use it to test the hypothesis of Chiang and Vimont (2004) that the TPMM is a physical mode triggered by extratropical atmospheric variability. We adopt an initial-value problem approach and conduct an ensemble experiment initialized on May 31 with subtropical mixed layer temperature anomalies in the northeast subtropical Pacific. The initial SST anomalies are assumed to be induced by changes in the northeast trades associated with mid-latitude atmospheric variability such as the North Pacific Oscillation (NPO; Vimont et al., 2001; CV04). The NPO-induced SST anomalies can persist from DJF to JJA (see the composite results of CV04). The initial mixed-layer temperature anomaly has an oval-shape distribution in the horizontal with an area-averaged amplitude of $1^{\circ} \mathrm{C}$, and is vertically uniform in the top $60 \mathrm{~m}$. The initial SST anomalies are much like Fig. 2a but confined to $145^{\circ} \mathrm{W}-91^{\circ} \mathrm{W}, 10^{\circ} \mathrm{N}-20^{\circ} \mathrm{N}$. Thirty runs are conducted, each starting with May 31 initial conditions taken from a different year in the long control simulation. The ensemble difference between the sensitivity and control experiments is taken as the coupled response to the initial warming.

The initial warm anomaly in the northeastern subtropics decays rapidly (Fig.2a) due 
to atmospheric damping associated with surface turbulent heat flux. The subtropical warming lowers in-situ atmospheric pressure and induces anomalous southwesterly winds on its southern flank. Superimposed on the prevailing easterlies, the anomalous southwesterlies reduce wind speed and surface evaporation, and cause a southwest displacement of the initial SST warming (Fig. 2b). To evaluate such atmospheric feedback, we cast the Newtonian cooling associated with surface latent heat flux as $\varepsilon T^{\prime}$ by linearizing the Clausius-Clapeyron equation (Xie, 1999). Here $\varepsilon=\frac{L \bar{Q}_{E}}{R \bar{T}^{2}}$, L is the latent heat of evaporation, $\mathrm{R}$ is the gas constant, $\mathrm{Q}_{\mathrm{E}}$ and $\mathrm{T}$ are surface latent heat flux and SST, respectively, the overbar and prime denote the values in and deviations from the control run. We then decompose surface latent heat flux into the Newtonian cooling and an atmospheric feedback term, $Q_{E}^{\prime}=\varepsilon T^{\prime}+\left(Q_{E}^{\prime}-\varepsilon T^{\prime}\right)$. The second term on the right hand side represents atmospheric feedback, say due to changes in wind speed. Figure 3 shows this atmospheric feedback term in latent heat flux. Positive feedback generally coincides with westerly wind anomalies, especially during June (Fig. 3a), indicating the importance of wind-induced evaporation. Precipitation increases over the subtropical warm SST anomaly, and wind anomalies at 250hPa are anticyclonic (not shown), opposite to surface cyclonic winds. The baroclinic atmospheric Rossby wave response to the subtropical SST warming - the anomalous southwesterlies and associated decrease in evaporation at the sea surface-is displaced southwest of the initial warming north of the equator. As a result, the subtropical SST warming displays a tendency to extend southwestward. On and south of the equator, the subtropical SST warming intensifies the prevailing 
southeastly trade winds and surface evaporation (Figs. 2a-b and 3a-b), helping cool SST there. This coupled response is consistent with the wind-evaporative-SST (WES) feedback as identified for the tropical Atlantic meridional mode (Chang et al., 1997; Xie, 1999).

Shortly after the subtropical warming is introduced, negative SST anomalies begin to develop on and slightly south of the equator, growing into amplitudes comparable to the northern warming during July and August (Fig. 2). The meridional dipole induced by the subtropical warming (Figs. 2b, c) resembles TPMM in the control simulation and observations. A heat budget analysis (not shown) indicates that intensified upwelling is the main cause of the equatorial cooling. In July, the anomalous southeasterlies increase the upwelling on and slightly south of the equator (Fig. 4b), and indeed, the maximum SST cooling is displaced south of the equator (Fig. 2b). The equatorial cooling, once formed, displays a tendency to move westward, along with the maxima of the southerly cross-equatorial wind and upwelling anomalies (Figs. 2-4).

After August, the SST dipole begins to decay because of the shift in the climatological wind. From June to September, the ITCZ continues its northward migration, and the climatological winds turn into southerly between the ITCZ and equator. Superimposed on these climatological southerlies, the southwesterly wind anomalies intensify surface evaporation and act to dampen the original SST warming. This effect of shifting climatological wind is reflected in the northward shift of the nodal line of the SST dipole; the WES feedback turns negative between the ITCZ and 
equator (Okajima et al., 2003).
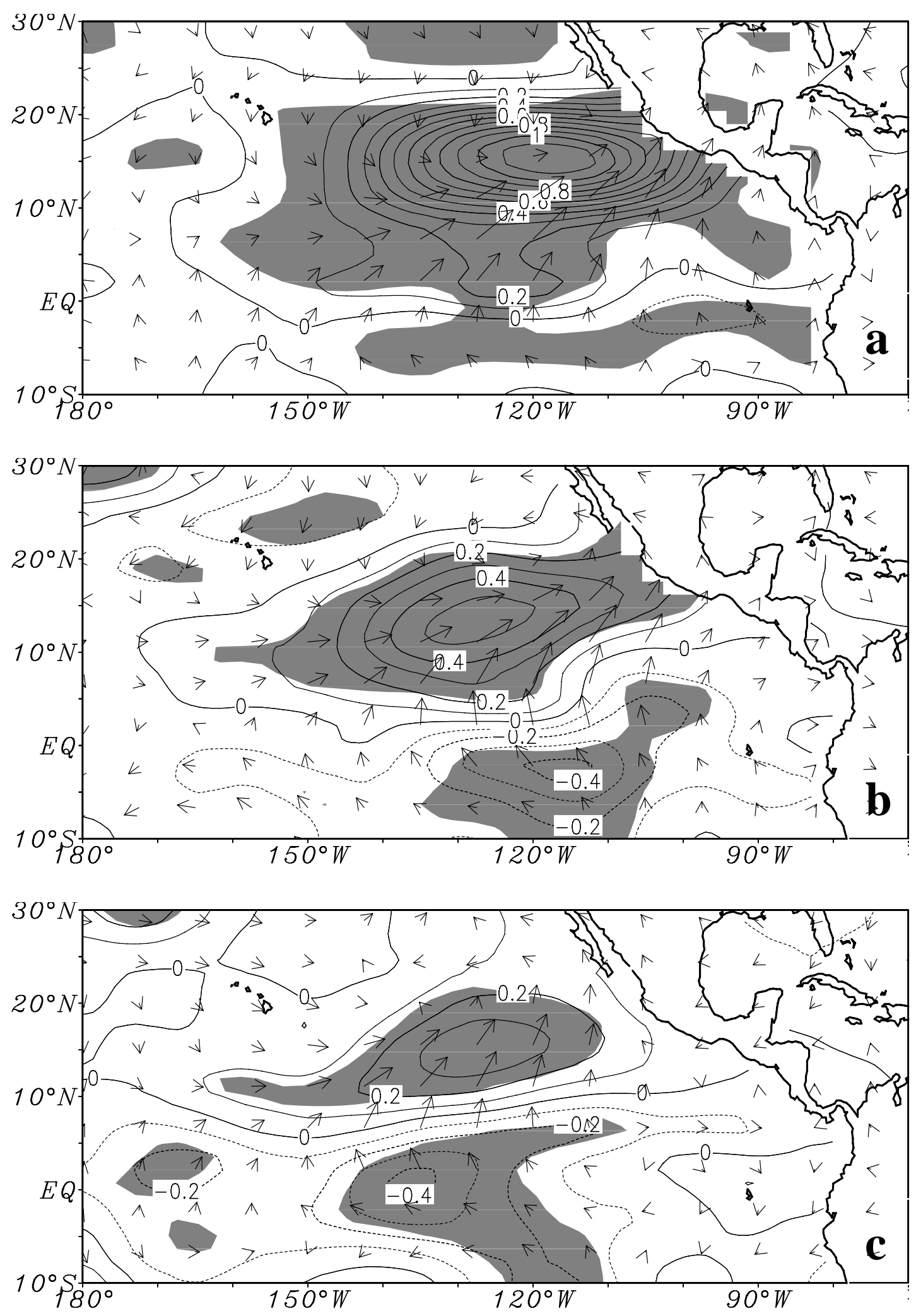

Fig. 2. SST (contours in ${ }^{\circ} \mathrm{C}$ ) and surface wind velocity (vectors in $\mathrm{ms}^{-1}$ ) anomalies in the sensitivity experiment for (a) June, (b) July, and (c) August. 
SST anomalies exceed the 95\% level of statistical significance in shaded areas.
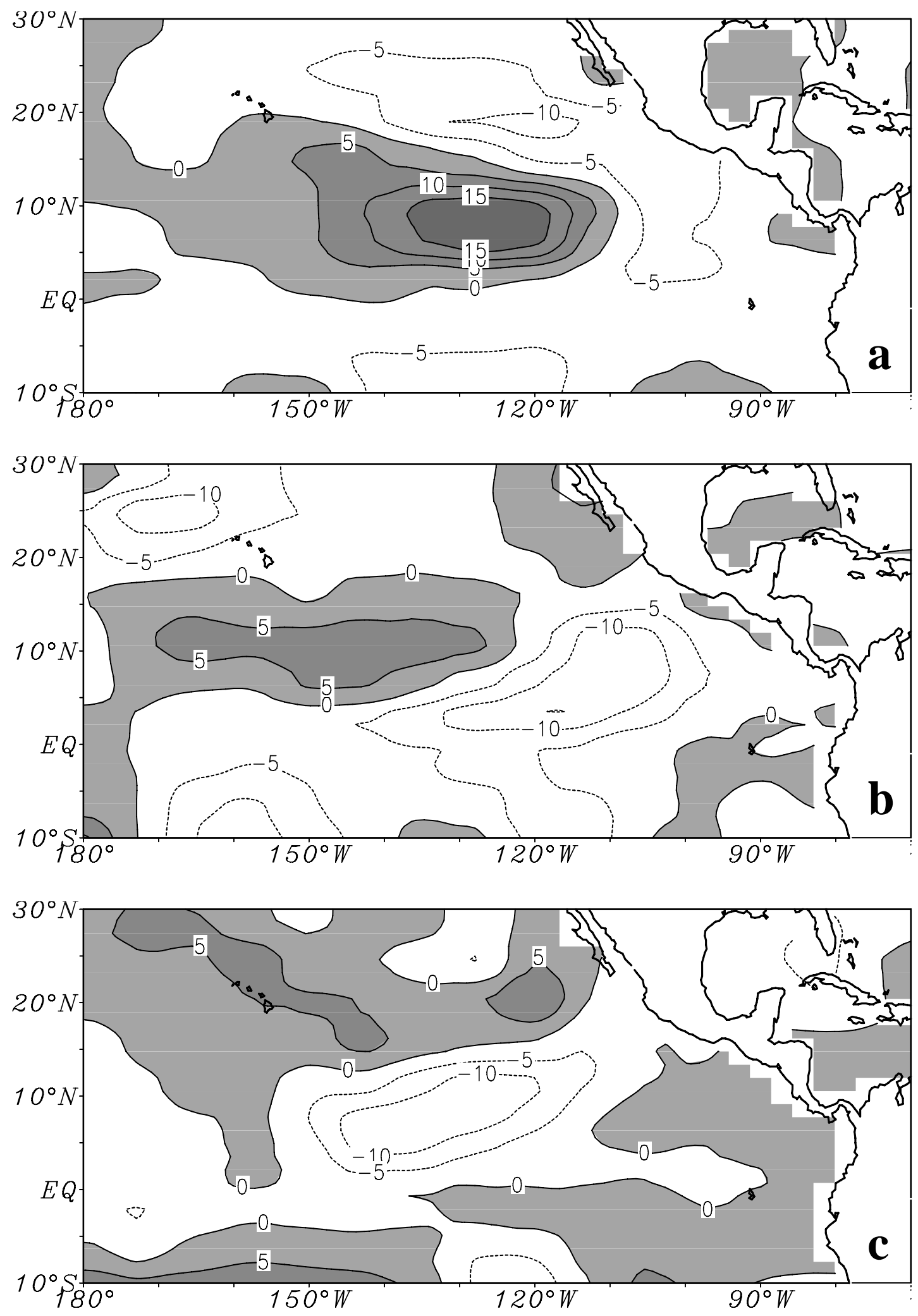

Fig. 3. Same as Fig. 2 but for latent heat flux minus the Newtonian cooling

$\left(\mathrm{Wm}^{-2}\right)$. Positive values are shaded and represent the ocean gaining heat. 

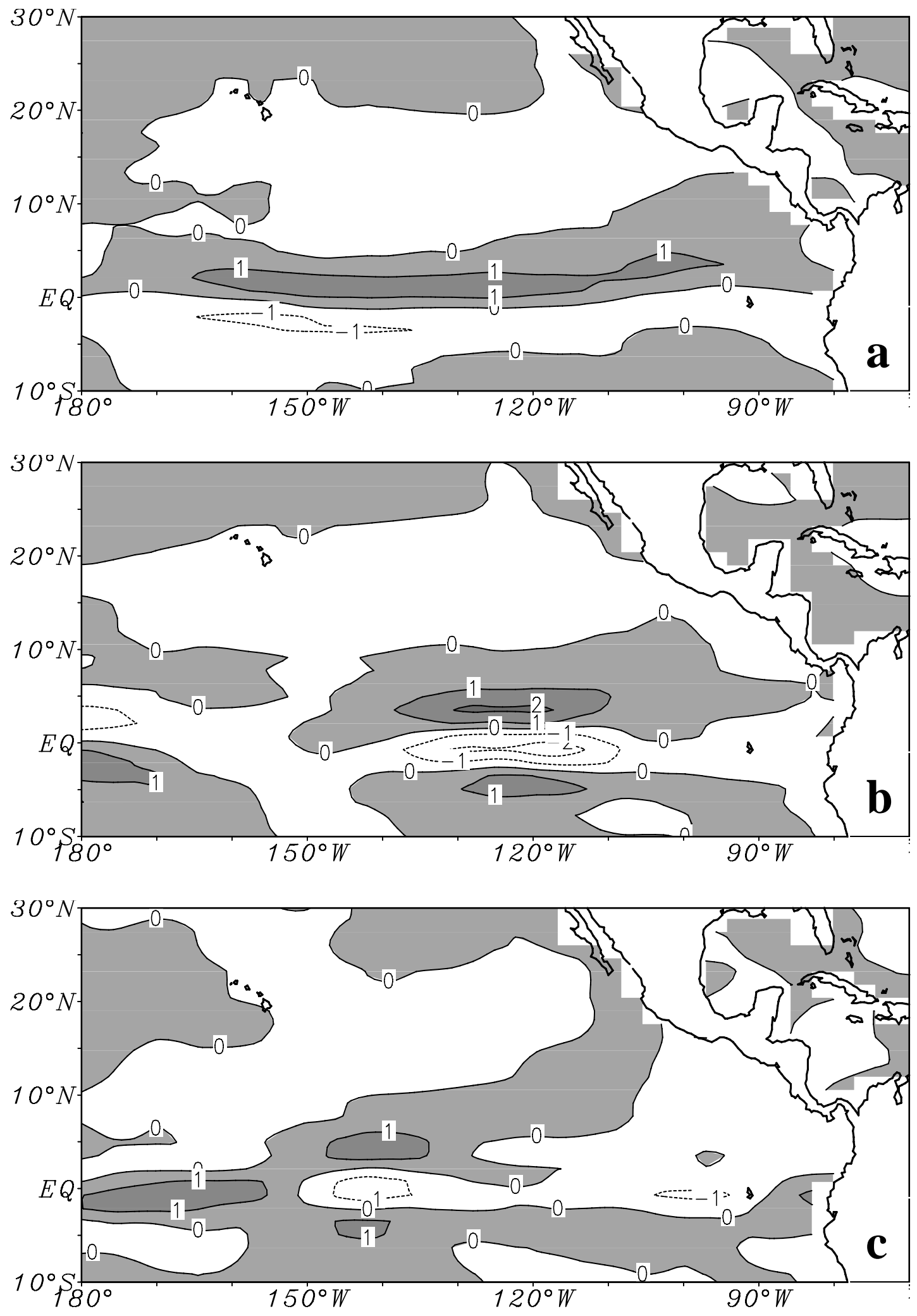

Fig. 4. Same as Fig. 2 but for vertical velocity $\left(10^{-6} \mathrm{~ms}^{-1}\right.$; positive downward) 
A parallel ensemble experiment with negative initial SST anomalies in the subtropical northeastern Pacific yields similar results except a sign difference. In another experiment with SST anomalies placed in the TPMM's southern lobe in the equatorial eastern Pacific, the model develops a Bjerknes mode with westward propagation along the equator. There tend to be SST anomalies of opposite sign north of the equator but the amplitude is small.

\section{Conclusions and discussion}

We have used a coupled model to investigate the mechanisms for developing the TPMM in late spring and early summer. The model TPMM in the control run resembles observations in both spatial structure and seasonal phase lock, with April-July as the preferred season for development. In the initial-value problem, an SST warming in the subtropical northeastern Pacific quickly develops into a TPMM-like meridional dipole, with the cool pole on the equator. The WES feedback induces a tendency for the initial subtropical warming to extend southwestward and reach the central Pacific while intensified upwelling appears to be the main cause of the equatorial cooling. The SST dipole begins to decay in late summer because the climatogical winds are southerly and the WES feedback turns negative between the equator and northerly ITCZ. These results support the CV04 hypothesis that the TPMM is a physical mode triggered by subtropical wind variability associated with the North Pacific Oscillation.

The results from our initial value problem suggest that the TPMM can indeed develop during spring to summer but this window of TPMM development does not 
extend into fall. This raises a question of why the TPMM prefers decadal timescales, if such a preference for timescales can be established from observations. Chang et al. (2007) suggest that TPMM often triggers El Nino in the subsequent summer. Since ENSO affects mid-latitude atmospheric variability, there is a possibility of tropical-extratropical interaction via TPMM. Our coupled model also shows a tendency for El Nino to follow TPMM. We are currently investigating why they happen in sequence and the implications for interaction between the tropics and mid-latitudes.

Acknowledgments. This work is supported by the ZhuFeng Projects of Ocean University of China (OUC), NSFC (40676010, 40333030), and Japan Agency for Marine-Earth Science and Technology. This work is also supported by the Luka Projects of Ocean University of China (OUC) with funding from the Chinese Ministry of Education. Discussions with Zhengyu Liu, Ping Chang, John Chiang and Li Zhang were helpful. All the simulations were carried at the OUC Ocean Data and Simulation Center. IPRC/SOEST publication \#xxx/yyy. 


\section{Reference}

Alexander, M.A., I. Blade, M. Newman, J.R. Lanzante, N.C. Lau, and J.D. Scott., 2002: The atmospheric bridge: The influence of ENSO teleconnections on air-sea interaction over the global oceans. J. Clim., 15, 2205-2231.

Bretherton, C.S., C. Smith, and J.M. Wallace, 1992: An Intercomparison of Methods for Finding Coupled Patterns in Climate Data, J. Clim., 5, 541-560.

Chang, P., L. Ji, and H. Li, 1997: A decadal climate variation in the tropical Atlantic Ocean from thermodynamic air-sea interactions, Nature, 385, 516-518.

Chang P., L. Zhang, R. Saravanan, D. J. Vimont, J. C. H. Chiang, L. Ji, H. Seidel, M. K. Tippett ,2007: Pacific meridional mode and El Niño-Southern Oscillation, Geophys. Res. Lett., 34, L16608, doi:10.1029/2007GL030302.

Chiang, J.C.H., and D.J. Vimont , 2004: Anologous Pacific and Atlantic Meridional Modes of tropical atmosphere-ocean variability, J. Clim., 17, 4143-4158.

Davey, M., and Coauthors, 2002: STOIC: A study of coupled model climatology and variability in tropical ocean regions, Clim. Dyn., 18,403-420.

Jacob, R. L., 1997: Low frequency variability in a simulated atmosphere ocean system. Ph.D. thesis, University of Wisconsin-Madison, 155pp.

Klein, S.A., B. J. Soden, and N.C. Lau, 1999: Remote sea surface temperature variations during ENSO: Evidence for a tropical atmospheric bridge, J. Clim., 12, 917-932.

Liu, Z., J. Kutzbach, and L. Wu, 2000: Modeling climate shift of El Niño variability in the Holocene, Geophys. Res. Lett., 27, 2265-2268. 
Okajima, H., S.-P. Xie, and A. Numaguti, 2003: Interhemispheric coherence of tropical climate variability: Effect of the climatological ITCZ, J. Meteor. Soc. Japan, 81, 1371-1386.

Vimont, D. J., D. S. Battisti, and A. C. Hirst, 2001: Footprinting: A seasonal connection between the tropics and mid-latitudes, Geophys. Res. Lett., 28, doi: 10.1029/2001GL013435.

Vimont, D.J., J. M. Wallace, and D. S. Battisti, 2003: The seasonal footprinting mechanism in the Pacific: Implications for ENSO, J. Clim., 6, 2668-2675.

Wang, C., and J. Picaut, 2004: Understanding ENSO physics-A review, Geophysical Monograph, 147, AGU, Washington D.C., 1-19.

Wu, L., Z.Y. Liu, C., Li, Y. Sun, 2007: Extratropical control of recent tropical Pacific decadal climate variability: A relay teleconnection, Clim. Dyn., 28, 99-112.

Xie, S.-P., 1999: A dynamic ocean-atmosphere model of the tropical Atlantic decadal variability, J. Clim., 12, 64-70. 